\title{
Disinfection efficacy of green synthesized gold nanoparticles for medical disinfection applications
}

\author{
Qionghui Huang ${ }^{1}$, Aihong Luo ${ }^{1}$, Lijuan Jiang ${ }^{1}$, Yan Zhou ${ }^{1}$, Yanting Yang ${ }^{1}$, Qiong Liu ${ }^{1}$, Chunfang Zhang ${ }^{2}$
}

1. Central sterile supply department, Xiangya Hospital, Central South University 410008.

2. Department of thoracic surgery, Xiangya Hospital, Central South University 410008.

\begin{abstract}
Background: In recent times, biosyntheses of metal nanoparticles were used for several life rescue applications. In this study, Dillenia indica leaf aqueous extract was utilized for the synthesis of gold nanoparticles.

Objective: To test anti-microbial properties of biologically fabricated gold nanoparticles.

Methods: Gold nanoparticles were efficiently prepared by making use of aqueous leaf extract of Dillenia indica. The excitation of formed AuNPs was confirmed using UV-Vis spectrophotometer. In particular, absorption spectra of AuNPs exhibited a well-defined SPR band centered at around $530 \mathrm{~nm}$.

Results: The high-resolution Scanning Electron Microscope (SEM) results of the obtained AuNPs confirmed the formation of particles with a size range of 5-50 nm. The ultra-high resolution TEM (UHRTEM) images displayed clear lattice fringes on the particle surfaces. Single crystalline nature of the biosynthesized AuNPs was represented by means of selected-area electron diffraction pattern.

Conclusion: The antibacterial activity of AuNPs revealed significant activity towards both gram negative and gram positive bacteria signifying their potential disinfection related applications in medicine and biology.

Keywords: Dillenia indica leaves, disinfection, AuNPs.

DOI: https://dx.doi.org/10.4314/ahs.v19i1.17

Cite as: Huang Q, Luo A, Jiang L, Zhou Y, Yang Y, Liu Q, et al. Disinfection efficacy of green synthesized gold nanoparticles for medical disinfection applications. Afri Health Sci. 2019;19(1). 1441-1458. bttps://dx.doi. org/10.4314/abs.v19i1.17
\end{abstract}

\section{Introduction}

Nanotechnology is a technology of art and science that deals with nanoscale materials ranging from 1 to $100 \mathrm{~nm}$ along with their applications ${ }^{1}$. Amongst various types of nanomaterials, noble metal nanomaterials have grabbed immense consideration owing to their exceptional optical, electronic, and catalytic properties ${ }^{2}$. In the recent times, gold nanoparticles (AuNPs) are extensively being explored because of their unique properties and uses in the field of biomedicine ${ }^{3}$. In particular, the multiple-surfacefunctionality of gold nanoparticles has facilitated their nanobiological adherence with oligonucleotides ${ }^{4}$. Drugs ${ }^{5}$. Protein $^{6}$, and antibodies ${ }^{7}$. Also, the optical nature of

\section{Corresponding author: \\ Chunfang Zhang, \\ NO.87, Xiangya road, Kaifu District, \\ Changsha, Hunan province, 410008, China \\ Email: zchunfang@yahoo.com}

AuNPs allows them to enact a significant role as marking agent in the science of bioimaging ${ }^{8}$. On the other hand, the bacterial existence in river and pond water has harmful effects on both human beings and living organisms, by causing long-standing diseases. To resolve the problems caused by these bacteria, several inorganic materials and nanomaterials have already been reported because of their very good anti-bacterial activity. Among them metal nanoparticles such as, gold and silver nanoparticles has got serious attention of researchers due to their anti-bacterial as well as biocompatible nature with high surface to volume ratios.

In spite of the use of physical and chemical methods for the synthesis of nanoparticles, there is still a critical requirement to develop environmentally benign procedures which do not include the use of highly toxic chemicals, particularly for the medical objective?. However, synthetic procedures that involve the use of natural products as reducing agents are needed to focus further in 
order to minimize their vulnerable effects on the nature and mankind. Green substrates like algae ${ }^{10,11}$, fungi ${ }^{12}$. and enzymes $^{13}$. were noted to be successfully employed in the synthesis of AuNPs. Moreover, owing to the complications suffered during microbial assisted synthesis ${ }^{14}$, plant mediated synthesis is being extensively developed in course because of its less difficult handling along with more easy control over the shape and size of nanoparticles. Plant mediated synthesis has many advantages as it is relatively safe and fast as well as successful even in room temperature conditions with no requirement to use more physical equipments ${ }^{15}$. Interestingly, almost every part of the plant is reported to be useful, in particular, the leaves ${ }^{16-19}$. while some other reports also focused even on thepeels of fruits ${ }^{20}$.

Recently, nanofibers, nanomaterials, nanoscaffolds and other biomaterials are being utilized as topical drug deliveryagents for wound healing. However, a significant proportion of nanomaterials are being employed in several biomedical applications for drug delivery,wound dressings together with other medical procedures ${ }^{21}$. It was reported earlier that secondary plant metabolites like alkaloids, flavonoids, terpenoids, and phenolic acid are engaged in the reduction of nanoparticles. To the best of our knowledge, there is no previous literature that discussed about Dillenia indica leaves extract in the preparation of AuNPs or any other metal nanoparticles. Here in this study, we have developed the biosynthesis and characterization of AuNPs by using aqueous extract of Dillenia indica leaf extract. Further, the obtained biosynthesized AuNPs were tested for their anti-bacterial activity to check their ability for disinfection. We chose the Dillenia indica plant extract for the green synthesis of NPs because the plant extract based methods are green, low cost and eco-friendly when compared to traditional chemical methods. Also, because of the harmful nature of reducing agents used, the obtained AuNPs can be used for environment and biological applications.

\section{Experiment \\ Materials}

Hydrogen tetrachloroaurate (III) $\left(\mathrm{HAuCl}_{4} 3 \mathrm{H}_{2} \mathrm{O}, 99.97\right.$ $\%$ ) was used as a precursor for the synthesis of AuNPs, which was obtained from Sigma-Aldrich, China. All the solutions were prepared with deionized water.

\section{Extract preparation}

Dried Dillenia indica leaves weighing about $1 \mathrm{gm}$ were crushed and made into powder. The obtained powder was then dispersed in $100 \mathrm{~mL}$ distilled water by gentle stirring followed by heating at $100{ }^{\circ} \mathrm{C}$ for about $30 \mathrm{~min}$. Mesh was used to filter the extract, followed by $0.2 \mu \mathrm{m}$ Millipore filter, and stored at $-20{ }^{\circ} \mathrm{C}$ before apply.

\section{Bio-mediated gold nanoparticle synthesis}

$20 \mathrm{~mL}$ of Dillenia indica leaves extract was mixed with 80 $\mathrm{mL}$ of $1 \mathrm{mM}$ Hydrogen tetrachloroaurate solution and placed in dark conditions with constant stirring for about $30 \mathrm{~min}$. The solution was further centrifuged for $30 \mathrm{~min}$ at $3000 \mathrm{rpm}$. The pellet and the supernatant were separated and pellet was placed in oven for $2 \mathrm{~h}$ for drying at $40{ }^{\circ} \mathrm{C}$.

\section{Antimicrobial activity}

The anti-microbial activity was conducted following agar well diffusion method. In brief, the bacterial suspension of both isolates of $S$. aureus and E. coli were cultivated for about $24 \mathrm{~h}$ which later made to $0.5 \mathrm{McF}$ arland turbidity standard. From the above both prepared suspension, about $100 \mu \mathrm{L}$ were spread onto Mueller-Hinton agar plates using sterile swabs followed by drying at room temperature. About $4 \mathrm{~mm}$ diameter wells were made into agar plate using cork borer maintaining an inter well distance of about $22 \mathrm{~mm}$. Then, AuNPs samples were loaded into all the wells at different concentrations. Later, the plates were allowed for incubation for $24 \mathrm{~h}$ at $37^{\circ} \mathrm{C}$. The transparent graph sheet was used to measure the diameters of inhibition.

\section{Characterization}

$\mathrm{X}$-ray diffraction (XRD) technique was used to analyze the phase purity which was recorded by means of diffractometer (XPERT-PRO) bearing nickel-filtered $\mathrm{Cu}(\lambda$ $=1.542 \AA$ ) at $40 \mathrm{kv}$ and $30 \mathrm{~mA}$. XRD pattern based on the line width of the $\left(\begin{array}{lll}1 & 1 & 1\end{array}\right)$ peak was used to determine the mean particle size of nanoparticles through the Debye-Scherrer method. FTIR spectrometer (Perkin-Elmer 1725X, Waltham, MA, USA) was employed to evaluate the mean size and particle size distribution of nanoparticles on the basis of TEM images. A simultaneous measurement of selected area electron diffraction (SAED) pattern is performed. UV-Vis spectrophotometer (a Lambda 25-Perkin Elmer, Waltham, MA, USA), was used 
to observe the UV-Visible absorption wavelength of samples in the range of $200-800 \mathrm{~nm}$.

\section{Result and discussions}

A comprehensive analysis on the Dillenia indica leaves extract mediated biomediated AuNPs was performed in this work. A change in the colour of medium was observed from yellow to light ruby red after $30 \mathrm{~min}$ and then altered to dark purple after $1 \mathrm{~h}$ of incubation has denoted the formation of AuNPs. The color alteration of the medium was determined by visual assessment.

-vis spectroscopy could be used to notice the reduction of the AuCl4-ions during the exposure to Dillenia indica leaf extract solution and formation of gold nanoparticles. Surface Plasmon Resonances (SPR) could be observed by the appearance of light ruby color due to the characteristic excitation of gold nanoparticles and formation of an absorption band at 510-545 $\mathrm{nm}$. Figure 1 represented the $\mathrm{UV}-$ vis absorption spectra of the reaction mixture obtained after 20 min of reaction. Clearly distinct SPR band absorption spectra of the formed AuNPs appeared at around $530 \mathrm{~nm}$. An increase in the number of nanoparticles owing to the reduction of gold ions in the aqueous solution was observed by an increase in the intensity of absorption wavelength. The clear dispersion of particles in the solution without much aggregation was signified by the sustainable AuNPs band at about $530 \mathrm{~nm}$ even after $24 \mathrm{~h}$ of incubation time.

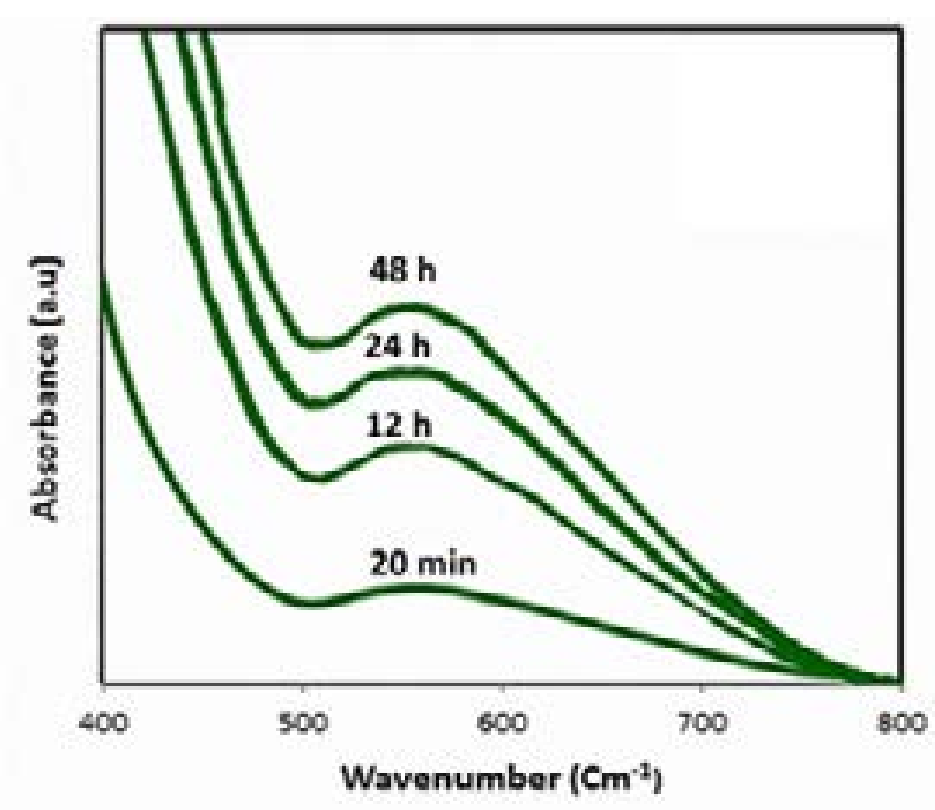

Figure-1.The UV-visible absorption spectra of the biosynthesized AuNPs. 


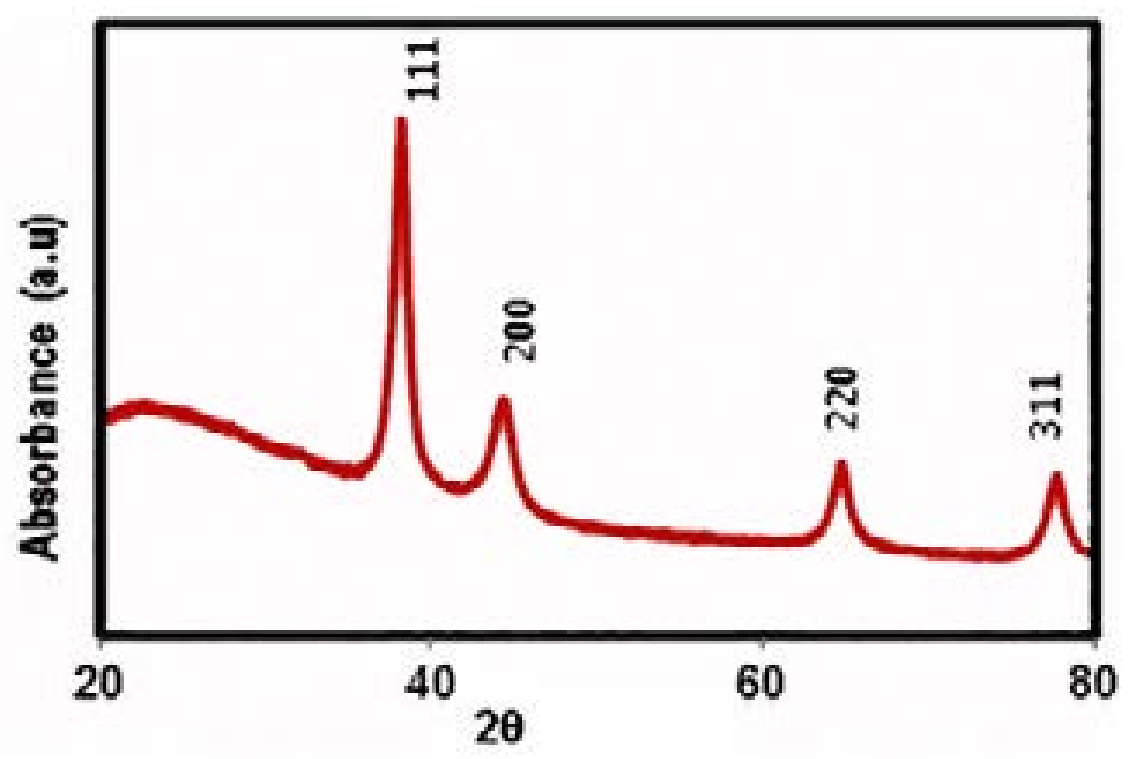

Figure-2.The XRD pattern of biosynthesized AuNPs.

Figure 2 disclosed the XRD pattern for biosynthesized AuNPs by making use of Dillenia indica leaves extract solution. The face-centred cubic structures of the obtained gold nanoparticles were detected by a number of Bragg reflections with $2 \theta$ values of $38.12^{\circ}, 44.34^{\circ}, 64.28^{\circ}$, and $77.63^{\circ}$ which refer to the (111), (200), (220), and (311) sets of lattice planes while broad Bragg's peaks denoted the formation of nanoparticles. However, the presence of some bio-organic compounds on the surface of prepared gold nanoparticles was attributed to the formation of sharp peaks.

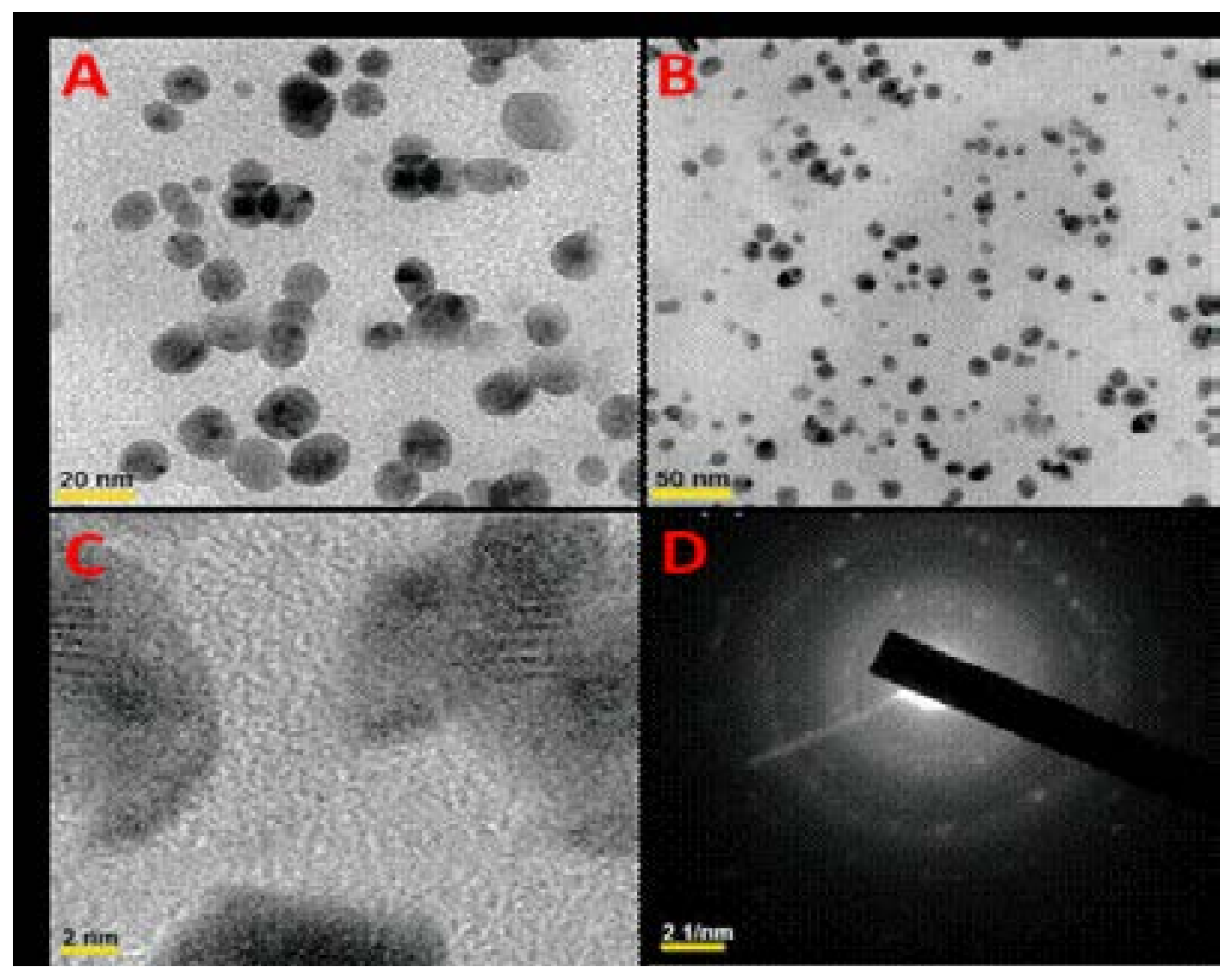

Figure-3.TEM images (A-C) and SAED pattern (D) corresponding to biosynthesizedAuNPs. 
Additionally, the formation of polydispersed and different shapes of AuNPs has been observed from the TEM images. As displayed in Figure 3 (A-C),characteristic size-distribution histogram and respectiveTEM images of the newly formed AuNPs have disclosed spherical shaped AuNPs with a broad spectrum of particle size. Further, the AuNPs formed at 20\% ACE signified the formation of gold naoparticles with the size ranging from
5-50 nm. The clear lattice fringes on the particle surfaces were represented by the ultra-high resolution TEM images. SAED pattern has disclosed the single crystalline nature of the biosynthesized AuNPs with the fcc phase. Figure 3D presented (111), (200) and (220) planes of the fcc crystalline lattice of AuNPs which were in accordance with the rings.

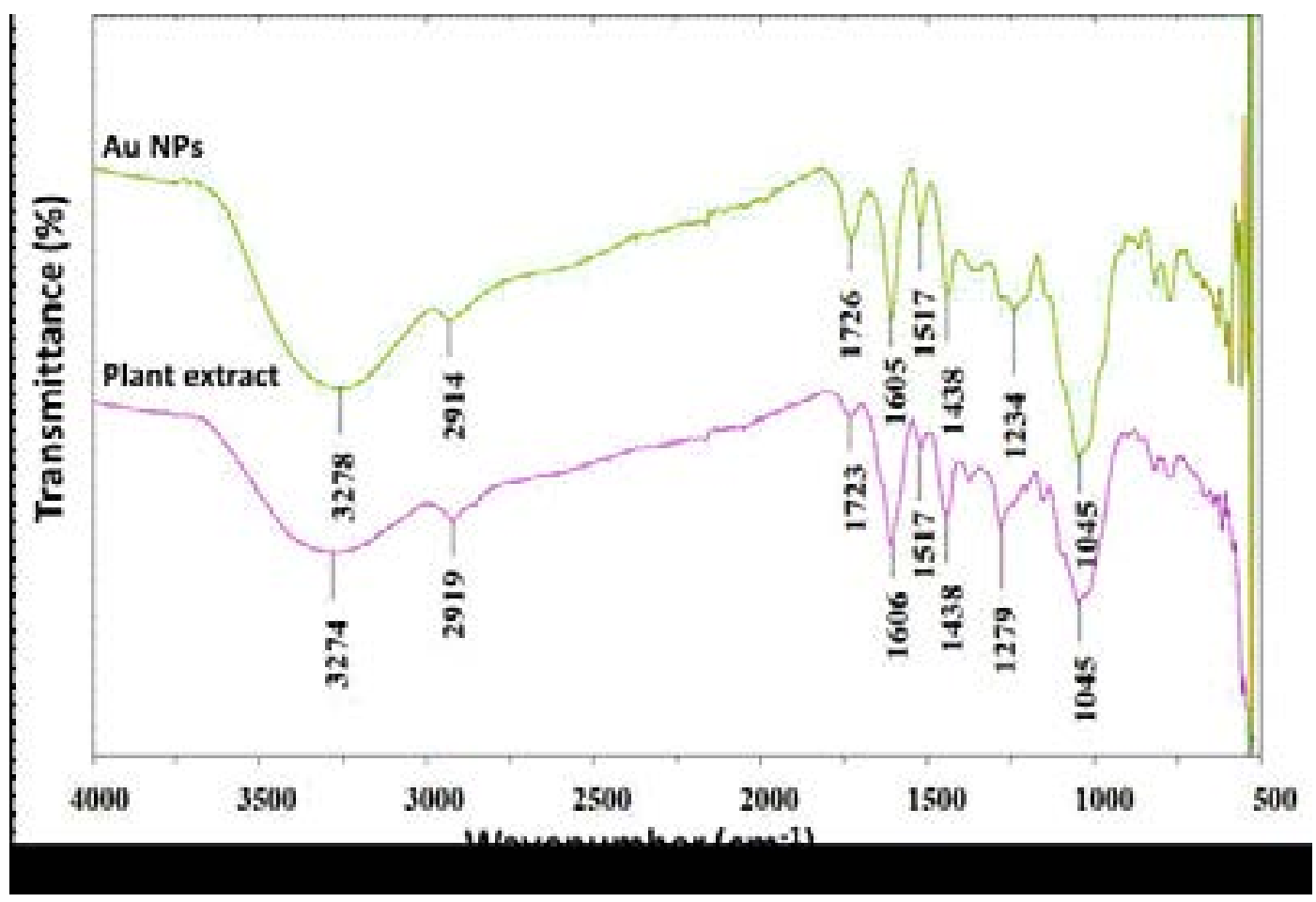

Figure-4.FT-IR spectrum of bio-synthesized gold nanoparticles

Further evaluation of the accounted functional groups that are essential for the reduction of AuNPs was carried out by means of FTIR spectroscopy. The spectra of pure Dillenia indica leaf extract along with that of Dillenia indica leaf extract-mediated AuNPs was shown in Figure 4. However, O-H stretching observed due to the existence of flavonoids, phenols, anthocyanins, and benzophenones was represented by the most significant stretching at $3000-3500 \mathrm{~cm}^{-1,23}$. Also, the carbonyl group of the leaf extract which played a crucial role in the capping and stabilization of the AuNPs was attributed to a minor shift ${ }^{24}$. The incidence of $\mathrm{C}-\mathrm{H}$ bond in xanthone and other compounds in the Dillenia indica leaf extract was denoted by the O-H stretching in the region of 2919 $\mathrm{cm}^{-1}$ and $2914 \mathrm{~cm}^{-1,25}$. The $\mathrm{C}-\mathrm{H}$ band splitting into two at different regions of $2914 \mathrm{~cm}^{-1}$ and $2845 \mathrm{~cm}^{-1}$ revealed the change of transmittance due to the formation of $\mathrm{AuNPs}^{26}$, while $\mathrm{C}=\mathrm{O}$ stretching was represented by a band at $1700 \mathrm{~cm}^{-1,27}$. However, the existence of aromatic rings in the Dillenia indica leaf extract was strongly supported by the incidence of a band around 1600-1500 $\mathrm{cm}^{-1}$. The presence of aromatic backbone in the Dillenia indica pericarp was denoted by the $\mathrm{C}-\mathrm{C}$ aromatic stretch bands at about 1500-1400 $\mathrm{cm}^{-1}$. Initially, C-O-C stretch appearedin the range of $1300-1000 \mathrm{~cm}^{-1}$, while a shift from $1279 \mathrm{~cm}^{-1}$ to $1234 \mathrm{~cm}^{-1}$ was observed due to capping with $\mathrm{AuNPs}^{28}$. Consequently, all these observations 
strongly inferred that the polyphenols of Dillenia indica leaf extract are functionally significant for the capping and reduction of $\mathrm{Au}+3$ to $\mathrm{Au} 0$ nanoparticles ${ }^{29,30}$.

\section{Anti-bacterial activity}

The effect of biosynthesized AuNPs are studied with concentrations of 1.0 and $1.5 \mathrm{mg} \mathrm{mL}^{-1}$ towards both $E$. coli (gram positive bacteria) and $S$. aureus (gram negative bacteria). The activity is performed by the well diffusion agar method (Shown in Fig. 5).

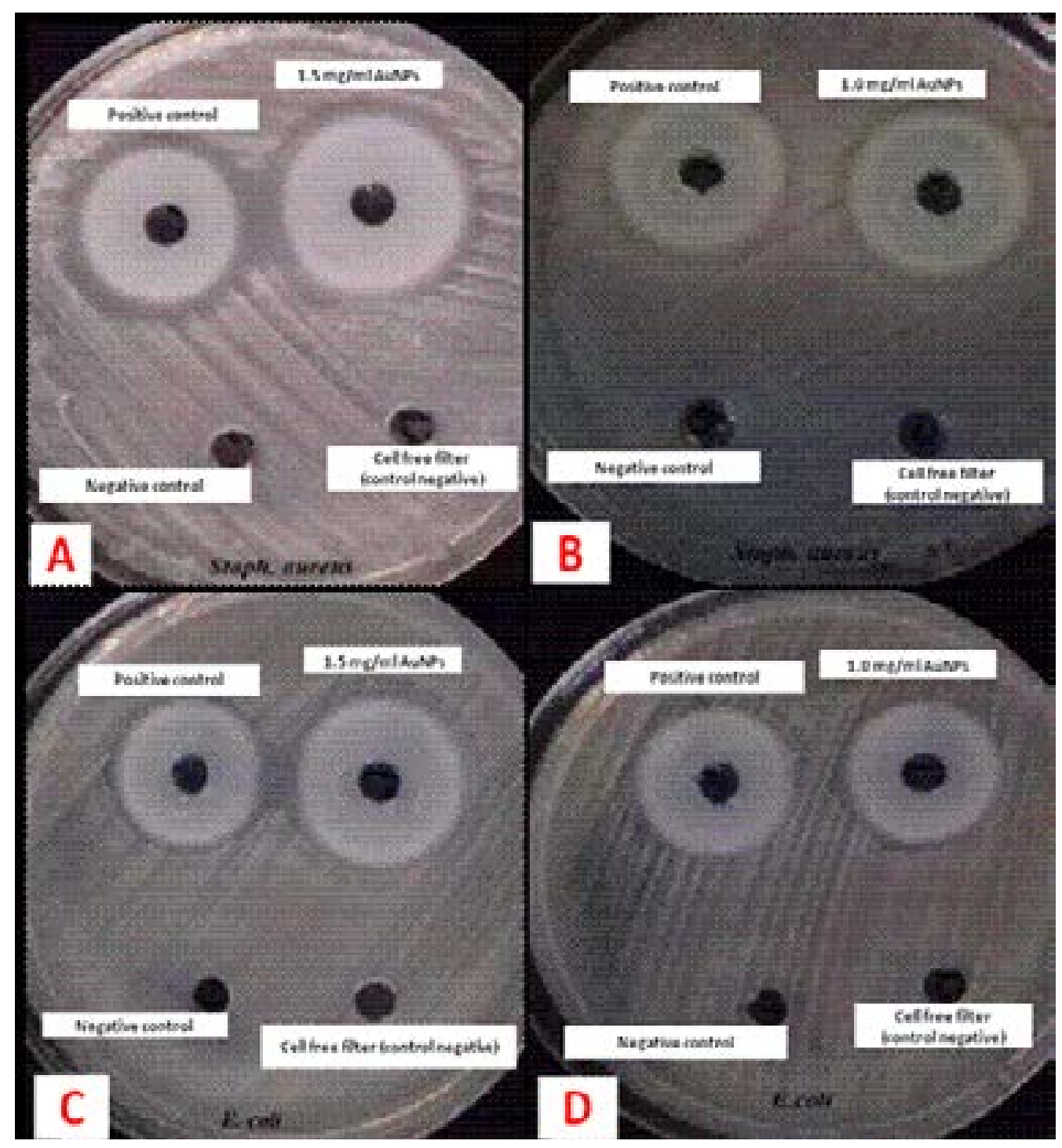

Figure-5. Antimicrobial activity of AuNPs used well diffusion test

From the examination results, it is found that AuNPs of 1.0 and $1.5 \mathrm{mg} \mathrm{mL}^{-1}$ prepared by using plant extracts exhibited very good anti-microbial activity towards gram negative $S$. aureus with corresponding zone of inhibition of about 23.5 and $25.5 \mathrm{~mm}$ correspondingly when compared with that of standard drug, Ciprofloxacin which is about $20 \mathrm{~mm}$. On the other hand, the gram positive bacteria E. coli has exhibited a zone of inhibition of about
25 and $28 \mathrm{~mm}$ when treated with the same concentration of AuNPs where as Ciprofloxacin showed a zone of inhibition of about $23 \mathrm{~mm}$. From the results, it can be concluded that biosynthesized AuNPs exhibited higher antibacterial effect towards gram positive bacteria than gram negative bacteria. It was also found that anti-bacterial activity of AuNPs is dose dependant and the obtained results are comparable to the treatment of stan- 
dard drug, Ciprofloxacin $\left(0.5 \mathrm{mg} \mathrm{mL} \mathrm{m}^{-1}\right)$. The increase in the anti-microbial activity of AuNPs with increase in the concentration may be because of the harmful effect of AuNPs with the cells with generation of reactive oxygen species resulting in the cell death. Further, the effective anti-microbial activity of prepared AuNPs signified their potential disinfection related applications in the scope of medicine and biology.

\section{Conclusion}

The synthesis of gold nanoparticles by means of Dillenia indica leaves extract was accomplished in an ecofriendly approach without making use of any toxic chemicals. The synthesized gold nanoparticles were subjected to different characterization techniques to estimate that they are polydispersed, consisting of various shapes like spherical, triangular, tetragonal, and pentagonal with irregular contoursspherically agglomerated particles with an average particle size of 5-50 nm. Furthermore, the antibacterial activity of AuNPs was examined which revealed significant activity towards both gram negative and gram positive bacteria signifying their potential disinfection related applications in the scope of medicine and biology.

\section{Acknowledgements}

Authors are thankful to Central South University, Changsha for providing platform to do this research.

\section{Conflict of interest}

None.

\section{References}

1. Zargar M, Hamid AA, Bakar FA, Shamsudin MN, Shameli K, Jahanshiri F, Farahani F. Green synthesis and anti-bacterial effect of silver nanoparticles using Vitexnegundo L. Molecules, 2011;16:6667-6676.

2. Rao KJ, Paria S. Aegle marmelos leaf extract and plant surfactants mediated green synthesis of $\mathrm{Au}$ and $\mathrm{Ag}$ nanoparticles by optimizing process parameters using taguchi method. ACS Sustainable Chem. Eng, 2015;3:483491.

3. Paciotti GF, Myer L, Weinreich D, Tamarkin L. Colloidal gold: a novel nanoparticle vector for tumor directed drug delivery. Drug Delivery, 2004;11:169-183.

4. Giljohann DA, Seferos DS, Patel PC, Millstone JE, Rosi NL, Mirkin CA. Oligonucleotide loading determines cellular uptake of DNA-modified gold nanoparticles. Nano Lett, 2007;7:3818-3821.
5. Mohamed MB, Adbel-Ghani NT, El-Borady OM, ElSayed MA. 5-Fluorouracil induces plasmonic coupling in gold nanospheres: new generation of chemotherapeutic agents. J. Nanosci. Nanotechno, 2012;3:1-7.

6. GengX, Grove TZ. Repeat protein mediated synthesis of gold nanoparticles: effect of protein shape on the morphological and optical properties. RSC Adv, 2015;5:20622069.

7. Ahmed M, Pan DW, Davis ME. Lack of in vivo antibody dependent cellular cytotoxicity with antibody containing gold nanoparticles. Bioconjugate Chem, 2015;26:812-816.

8. Yong KT, Swihart MT, Ding H, Prasad PN. Preparation of gold nanoparticles and their applications in anisotropic nanoparticle synthesis and bioimagin. Plasmonic, 2009;4:79-93.

9. Kuppusamy P, Yusoff MM, Ichwan SJA, Parine NR, Maniam GP, Govindan N. CommelinanudifloraL. edible weed as a novel source for gold nanoparticles synthesis and studies on different physical-chemical and biological properties. Ind. Eng. Chem, 2015;27:59-67.

10. Naveena BE, Prakash S. Biological synthesis of gold nanoparticles using marine algae Gracilariacorticataand its application as a potent antimicrobial and antioxidant agent. Asian J. Pharm. Clin. Res, 2013;6:179-182.

11. Khanehzaei H, Ahmad MB, Shameli K, Ajdari Z, Ghani MA, Kalantari K. Effect of seaweed Kappaphycusalvarezii in the synthesis of $\mathrm{Cu} @ \mathrm{Cu} 2 \mathrm{O}$ core-shell nanoparticles prepared by chemical reduction method. Res. Chem. Intermediat, 2015;41:7363-7376.

12. Dhanasekar NN, Rahul GR, Narayanan KB, Raman G, Sakthivel N. Green chemistry approach for the synthesis of gold nanoparticles using the fungus Alternariasp. J. Microbiol. Biotechnol, 2015;25:1129-1135.

13. Narayanan KB, Sakthivel N. Facile green synthesis of gold nanostructures by NADPH-dependent enzyme from the extract of Sclerotiumrolfsii. Colloids Surf A Physicochem Eng Asp, 2011;380:156-161.

14. Zhang X, Yan S, Tyagi RD, Surampalli RY. Synthesis of nanoparticles by microorganisms and their application in enhancing microbiological reaction rates. Chemosphere, 2011;82:489-494.

15. Chung IM, Park I, Seung-Hyun K, Thiruvengadam M, Rajakumar G. Plant-mediated synthesis of silver nanoparticles: their characteristic properties and therapeutic applications. Nanoscale Res. Lett, 2016;11:1-14.

16. Philip D. Rapid green synthesis of spherical gold nanoparticles using Mangiferaindica leaf. Spectrochim. Acta. A, 2010;77:807-810. 
17. Dash SS, Bag BG, Hota P. Lantana camara Linn leaf extract mediated green synthesis of gold nanoparticles and study of its catalytic activity. Appl. Nanosci, 2015;5:343-350.

18. Kumar VG, Gokavarapu SD, Rajeswari A, Dhas TS, Karthick V, Kapadia Z, Shrestha T, Barathy IA, Roy A, Sinha $S$. Facile green synthesis of gold nanoparticles using leaf extract of antidiabetic potent Cassia auriculat. Colloids and Surf B Biointerfaces, 2011;87:159-16.

19. Sadeghi B, Mohammadzadeh M, Babakhani B. Green synthesis of gold nanoparticles using Stevia rebaudianaleaf extracts: characterization and their stability. J. Photochem. Photobio. B, 2015;148:101-106.

20. Yang N, Weihong L, Hao L. Biosynthesis of Au nanoparticles using agricultural waste mango peel extract and its in vitro cytotoxic effect on two normal cells. Mater. Lett, 2014;34:67-70.

21. Lara Y, Nguyen TK, Marilena L, Alexander M. Toxicology and clinical potential of nanoparticles. Nano Today, 2011;6:585-607 PubMed.

22. Lin J, Chen R, Feng S, Pan J, Li Y, Chen G. A novel blood plasma analysis technique combining membrane electrophoresis with silver nanoparticle-based SERS spectroscopy for potential applications in non-invasive cancer detection. Nanomed.: Nanotechnol., Biol. Med, 2011;7:655-663. PubMed.

23. Rao KJ, Paria S. Aegle marmelos leaf extract and plant surfactants mediated green synthesis of $\mathrm{Au}$ and $\mathrm{Ag}$ nanoparticles by optimizing process parameters using taguchi method. ACS Sustain. Chem. Eng, 2015;3:483491. PubMed.

24. Gan PP, Ng SH, Huang Y, Li SFY. Green synthesis of gold nanoparticles using palm oil mill effluent (POME): a low cost and eco-friendly viable approach. Biores. Tech, 2012;113:132-135.

25. Shameli K, Ahmad MB, Shabanzadeh P, Jaffar Al-Mulla EA, Zamanian A, Abdollahi Y, Jazayeri SD, Eili M, Jalilian FA, Haroun RZ. Effect of Curcuma longa tuber powder extract on size of silver nanoparticles prepared by greenmethod. Res. Chem. Inter, 2014;40:1313-1325.

26. Das RK, Gogoi N, Bora U. Green synthesis of gold nanoparticles using Nyctanthesarbortristis flower extract. Biopro. Biosys. Eng, 2011;34:615-619.

27. Bogireddy NKR, Anand KKH, Mandal BK. Gold nanoparticles - synthesis by Sterculiaacuminata extract and its catalytic efficiency in alleviating different organic dyes. J. Mol. Liq, 2015;211:868-875.

28. Sathiyanarayanan G, Vignesh V, Saibaba G, Vinothkanna A, Dineshkumar K, Viswanathan MB, Selvin J. Synthesis of carbohydrate polymer encrusted gold nanoparticles using bacterial exopolysaccharide: a novel and greener approach. RSC Adv, 2014;4:22817-22827.

29. Agnihotri S, Mukherji S, Mukherji S. Size-controlled silver nanoparticles synthesized over the range 5-100 nm using the same protocol and their anti-bacterial efficacy. RSC Adv, 2014;4:3974-3983. PubMed.

30. Maddinedi SB, Mandal BK, Maddili SK. Biofabrication of size controllable silver nanoparticles -a green approach. J. Photochem. Photobiol. B, 2017;167:236-241. 